\title{
Relativas livres e interrogativas parciais: paralelos e diferenças ${ }^{1}$ Gabriela Matos
}

Faculdade de Letras da Universidade de Lisboa/Centro de Linguística da Universidade de Lisboa Ana Maria Brito

Faculdade de Letras da Universidade do Porto/Centro de Linguística da Universidade do Porto

\begin{abstract}
:
In this paper we analyse parallelisms and differences between free relatives, true embedded wh interrogatives, and improper embedded wh interrogatives. While free relatives are DPs which contain a CP, embedded wh interrogatives, both true and improper interrogatives, are CPs. In the last years and in the framework of the Minimalist Program, this different categorial nature has been deduced from formal labelling conditions, mainly related to the nature of head or maximal projection of the moved wh constituent. In this paper, while not rejecting the importance of the difference between head and maximal projection of the wh constituent, we show that the DP or CP nature of the embedded constituent and its [+int] or [+decl] status must be sanctioned by the selection requirements of the matrix predicate.
\end{abstract}

Keywords: free relatives, embedded wh interrogatives, wh movement, head, labelling

Palavras-chave: relativas livres, interrogativas parciais subordinadas, movimento $w h$, núcleo, etiquetagem

\section{Introdução}

Em línguas como o português, as orações relativas livres apresentam propriedades que as aproximam das interrogativas parciais subordinadas; assim, tanto as relativas livres como as interrogativas parciais subordinadas $^{2}$ em (1) e (2), nas alienas a. e b. respetivamente, são iniciadas pelas expressões quem ou o que, designadas usualmente como expressões- $Q u-$, ou, em inglês, expressões- $w h$ :

(1) a. O Renault Laguna surpreende quem, como eu, não gosta particularmente de carros tipo familiar.(CRPC,R1837)

(2) a. Cumpra o que prometeu, invista na investigação da sida.

(CETEMPúblico 1.7 v. 7.7, par=ext435444-pol-93a-1)

b. Pode é perguntar-se o que sucederia sem o Plano.

(CETEMPúblico 1.7 v. 7.7, par=ext518885-pol-92a-2)

\footnotetext{
${ }^{1}$ A investigação apresentada neste trabalho foi realizada no âmbito do Centro de Linguística da Universidade do Porto - Unidade FCT UID/LIN/0022/2016 Ana Brito) e da UID/LIN/00214/201, unidade de I\&D financiada pela Fundação para a Ciência e a Tecnologia (Gabriela Matos). O trabalho foi apresentado no XXXIII Encontro da Associação Portuguesa de Linguística, que decorreu na Universidade de Évora, de 27 a 29 de setembro de 2017. Agradecemos aos participantes e principalmente a dois revisores anónimos as observações e as propostas de melhoria.

${ }^{2}$ Quer as interrogativas parciais quer as interrogativas globais encaixadas e selecionadas por um V matriz têm recebido nos estudos gramaticais a designação de 'interrogativas indiretas'. Como as designações de 'direta' e 'indireta' podem ter uma incidência pragmática, no texto usaremos preferencialmente a designação de 'subordinadas'.
} 

Porém, desde há muito tem sido salientado que, para lá das semelhanças, há também diferenças de interpretação e estruturais que distinguem estas construções. No quadro da gramática generativa, vejam-se, por exemplo Brito (1991), Brito \& Duarte (2003), Móia (1996), Veloso (2013), Matos \& Brito (2013), Mioto \& Lobo (2016).

No presente trabalho propomo-nos discutir a análise sintática deste tipo de construções, à luz de desenvolvimentos recentes do Programa Minimalista (Chomsky, 2008, 2013, 2015), Cecchetto \& Donati (2010, 2015), Donati \& Cecchetto (2011), Rizzi (2015, 2016a,b).

O texto está organizado da seguinte maneira: no ponto 2. apresentam-se as principais propriedades sintáticas das duas construções, as quais permitem considerar que as interrogativas subordinadas são um argumento oracional do predicado matriz enquanto as relativas livres se comportam como orações integradas num argumento nominal; no final deste ponto referem-se alguns casos que podem representar ocorrências de ambiguidade estrutural. Em 3.apresentam-se algumas análises sintáticas clássicas sobre estas duas construções, para, em 4., discutirmos algumas propostas surgidas no Programa Minimalista, baseadas nas noções de Compor, Estrutura Sintagmática Nua e Etiquetagem. Em 5., faremos uma proposta de análise sintática, procurando, em especial, avaliar se as propostas recentes surgidas no quadro do Programa Minimalista permitem prescindir de ou antes devem articular-se com mecanismos de análise anteriormente avançados na literatura. Em 6. apresentaremos breves conclusões.

\section{Relativas livres e interrogativas parciais - caracterização sintática}

\subsection{Algumas semelhanças}

Como referido na literatura, uma propriedade aproxima relativas livres de interrogativas parciais subordinadas em português - em ambas opera um movimento que desloca para a posição inicial da frase encaixada o constituinte- $w h^{3}$; vejam-se os exemplos (3) e (4):

(3) a. Cumpra o que prometeu.

b. *Cumpra prometeu o que.

(4) a. Não sei a quem hei de dar a palavra.

b. *Não sei hei de dar a palavra a quem.

Embora nas interrogativas parciais a permanência do constituinte-wh in situ seja possível em contextos discursivos específicos ${ }^{4}$, como é visível em (5), esta estratégia está vedada às interrogativas subordinadas (note-se a agramaticalidade de 6b). Exemplos como (6c) não constituem contra-argumentos a esta generalização, uma vez que o que temos em (6c) é uma interrogativa direta ${ }^{5}$ :

(5) A quem hei de dar a palavra? /Hei de dar a palavra a quem?

(6) a. Pergunto-me a quem hei de dar a palavra.

b. *Pergunto-me hei de dar a palavra a quem.

c. Pergunto(-me): Hei de dar a palavra a quem?

\footnotetext{
${ }^{3}$ Por estarem muito divulgadas nos estudos sintáticos, usaremos as siglas das categorias em inglês, assim como a própria designação de palavra ou sintagma-wh para os constituintes interrogativos / relativos.

${ }_{4}^{4}$ A estratégia in situ das interrogativas parciais é cada vez mais frequente na oralidade como forma de produzir uma verdadeira pergunta e não apenas como pergunta em eco.

${ }^{5}$ Nem todos os predicados que selecionam interrogativas subordinadas podem introduzir interrogativas diretas. É o caso de desconhecer, não saber, etc.
} 

Em suma, tanto nas relativas livres como nas interrogativas parciais encaixadas opera o que classicamente se designou por movimento-wh, ilustrado, para os exemplos em (7), na representação simplificada em (8):

(7) a. Pergunto o que fizeste.

b. Admiro o que fizeste.

(8)

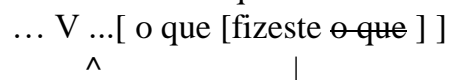

Considerando apenas a propriedade de obrigatoriedade de movimento do constituinte wh, a estrutura subordinada representada em (8) comporta-se como estruturalmente ambígua, no sentido em que tanto pode ocorrer encaixada numa relativa livre como numa interrogativa parcial subordinada.

\subsection{Propriedades distintivas entre relativas livres e interrogativas indiretas}

Tem sido destacado para várias línguas que as relativas livres e as interrogativas subordinadas têm interpretações e comportamentos diversos. Para o português, veja-se Brito (1991), Brito \& Duarte (2003), Móia (1996), Veloso (2013), Mioto \& Lobo (2016):

(i) As relativas livres apresentam contrapartidas em relativas com antecedente realizado - Cf. (1a), (2a), (7b) vs. (9):

(9) a. O Renault Laguna surpreende qualquer pessoa que (..) não gosta particularmente de carros tipo familiar.

b. Cumpra aquilo que prometeu,...

c. Admiro as coisas que fizeste.

Pelo contrário, as interrogativas subordinadas não admitem tipicamente paráfrases com relativas com antecedente - cf. (1b), (2b) vs. (10):

${ }^{6}$ Como referido em Peres \& Móia (1995: 92) e em Matos \& Brito (2013), para o português, certos predicados de inquirição e de desconhecimento, que podem ser formados pelo verbo e as unidades que o modificam, nomeadamente o marcador de negação frásica, como não saber em (ii), podem ser seguidos de DPs (i) ou de DPs seguidos de relativas restritivas (ii):

(i) Perguntei as horas.

(ii) O Luís não sabe o caminho (que deve tomar).

Tendo em vista a sua interpretação semântica e a existência de frases interrogativas subordinadas correlatas, como (iii) e (iv), expressões como (i) e (ii) foram designadas em estudos de teor semanticista como "concealed questions" (ver, por exemplo, Frana 2006), ou, no português, "interrogativas reduzidas ou elíticas" (Peres \& Móia 1995). No entanto, de um ponto de vista sintático, o complemento dos predicados de inquirição perguntar e não saber, em (i) e (ii), é um DP e, portanto, não exibe verdadeiramente força ilocutória interrogativa, ao contrário das interrogativas subordinadas parciais correspondentes (como (iii) e (iv)):

(iii) Perguntei que horas são.

(iv) O Luís não sabe que caminho deve tomar.

A possibilidade de exemplos como (i) e (ii) não invalida, por isso, a afirmação de que os predicados de inquirição (elencamo-los adiante, em (iv)) selecionam tipicamente argumentos oracionais.

Como veremos na secção 2.3, existem casos na fronteira entre as interrogativas e as declarativas (que, de acordo com a literatura vigente, designamos por interrogativas impróprias ou falsas interrogativas) e que admitem a alternância com relativas com antecedente (v)-(vi). Note-se que, neste caso, o predicado superior (lexicalmente restringido) não exibe um valor de inquirição e pode exibir posse de conhecimento, como ilustram os exemplos em (v)-(vi), em que o verbo saber, contrasta com não saber em (ii):

(v) O Luís sabe que caminho deve tomar.

(vi) O Luís sabe o caminho que deve tomar.

Para uma discussão alargada destas construções e uma apresentação das propriedades que lexical e sintaticamente as afastam das "concealed questions" veja-se Matos \& Brito (2013). 

(10) a. *Srs. Deputados, não sei as pessoas a que $(\mathrm{m})$ hei de dar a palavra.

b. ??Pode é perguntar-se as coisas que sucederiam sem o Plano.

(ii) A substituição das interrogativas subordinadas por um sintagma de natureza nominal é muito mais restringida do que nas relativas livres: ${ }^{7}$

(11) a. Pergunto $\{\sqrt{ }$ isso $/$ ? essa questão $/ *$ essa atitude/*essa causa $\}$

b. Não sei $\{\sqrt{ }$ isso $/$ ?essa questão /*?essa atitude $/ *$ essa causa $\}$

(12) a. Admiro $\{\sqrt{ }$ isso $/ \sqrt{ }$ essa atitude/ $\sqrt{\text { essa causa } / \text { ?essa questão }\}}$

b. Cumpro $\{\sqrt{ }$ isso $/ \sqrt{ }$ a lei $/ \sqrt{ }$ a minha obrigação/ $/$ todas as promessas $\}$

(iii) As relativas livres podem ocorrer com predicados que não selecionam argumentos frásicos, como é visível pela agramaticalidade de (13c, d), com cumprir, e (14c) com comprar. ${ }^{8}$

(13) a. Cumpra o que prometeu.

b. Ele cumpriu a lei.

c. *Ele cumpriu que a lei fosse aplicada.

d. *Ele cumpriu aplicar a lei.

(14) a. Eu comprei o que estava na montra.

b. Eu comprei esses livros.

c. *Eu comprei que os livros estavam na montra.

(iv) As interrogativas parciais subordinadas são selecionadas por predicados que aceitam tipicamente argumentos oracionais:

a) predicados superiores de inquirição: perguntar( -se), inquirir, querer saber; ...

b) predicados superiores de desconhecimento: ignorar, desconhecer, não saber,...

c) predicados de dizer e de perceção (e.g. dizer, admitir, ver, ouvir) sob o escopo de um elemento negativo, ou sob o escopo de um operador de interrogação:

Em (15) os argumentos oracionais selecionados por estas classes de predicados são as chamadas "interrogativas subordinadas parciais" e por isso são iniciadas por morfemas $w h$ :

(15) a. Ele inquiriu/perguntou/ quis saber quem estava na sala na altura da votação.

b. Ele não sabe o que aconteceria sem o Plano.

c. Ele não viu quem/ que pessoa (é que) o cumprimentou?

Em (16) os mesmos predicados selecionam "interrogativas subordinadas globais” e, por essa razão, admitem a construção de se+oração; tal não sucede com os predicados que selecionam relativas livres, como é visível pela agramaticalidade dos exemplos em (17): ${ }^{9}$

${ }^{7}$ Como já sugerido na nota anterior, esta propriedade depende muito do predicado superior; para uma discussão ver, entre outros, Peres \& Móia (1995) e Matos \& Brito (2013).

${ }^{8}$ Além disso, podem ocorrer em contextos não subcategorizados (de sujeito, de predicado), ver Brito \& Duarte (2003).

${ }^{9}$ Naturalmente, predicados como surpreender e admirar também são capazes de selecionar argumentos oracionais, mas declarativos:

(i) Surpreende-me que tenhas vindo tão tarde;

(ii) Admira-me que tenhas vindo tão tarde. 

(16) a. Pergunto se sucederia alguma coisa sem o Plano.

b. Não sei se hei de dar a palavra (já) a vários deputados.

(17) a. *O Renault Laguna surpreende se qualquer pessoa não goste de carros tipo familiar.

b. *Admiro se fizeste isso.

(v) As interrogativas subordinadas, como (18), e ao contrário das relativas livres no português europeu padrão (19), podem co-ocorrer com é que: ${ }^{10}$

(18) Pergunto/ignoro o que é que fizeste.

(19) a. *Ele cumpriu o que é que tinha prometido.

b. *Ele fotografou quem é que estava na sala.

(vi) As interrogativas subordinadas, diferentemente das relativas livres (21), não apresentam efeitos de ilha quando há extração de um constituinte da subordinada (20):

(20) a. A Teresa a quem eu ignoro quem escreveu _tem muitos namorados.

(Brito 1991)

b. Este é o livro que o professor não sabe quem leu _.

(Móia 1996)

(21) a. *A Teresa a quem eu detesto quem escreveu_tem muitos namorados.

b. *Este é o livro que o professor elogiou quem leu _.

(Brito 1991)

(Móia 1996)

Tendo em vista propriedades como as apresentadas, tem sido assumido que as interrogativas parciais subordinadas funcionam como argumentos oracionais do verbo superior, usualmente como seu argumento interno, isto é, as interrogativas parciais subordinadas são frases. Por seu lado, as relativas livres estão integradas numa estrutura de natureza nominal e funcionam como modificadores de um constituinte nominal sem realização lexical (Brito, 1991; Móia,1996; Veloso, 2013; Mioto \& Lobo, 2016) ${ }^{11}$

\subsection{Casos problemáticos}

Existem casos que não se enquadram nas relativas livres nem nas interrogativas parciais subordinadas que temos vindo a apresentar; trata-se de construções que têm sido designados na literatura como falsas interrogativas ou interrogativas impróprias. Tais construções foram atestadas para o espanhol desde o início dos anos 90 (Suñer1991, 1993, 1999) e, como mostraram Matos \& Brito (2013), ocorrem também no português europeu. Como o exemplo em (22a) mostra, as interrogativas impróprias são tipicamente ilustradas

\footnotetext{
${ }^{10}$ Cardoso \& Alexandre (2013) encontraram no corpus do CORDIAL-SIN algumas relativas livres com é que:

(i) "Portanto, o que é que cai é a neve e da neve faz água."

(ii) "Quem é que tinha matado aquele bicho casava com a filha."

Recorde-se que o corpus do CORDIAL-SIN resulta de transcrições de excertos de discurso espontâneo ou semi-dirigido, constituído por produções orais selecionadas de inquéritos dialetais representativos de 42 localidades ou micro-regiões no território português continental e insular. A proveniência é sociolinguisticamente homogénea, sendo as amostras produzidas por falantes naturais e residentes nas localidades rurais inquiridas, idosos e pouco escolarizados ou analfabetos.

Cardoso \& Alexandre (2013) consideram que nas frases ilustradas acima há uma leitura de foco e de exaustividade, que pode ter uma paráfrase com advérbios do tipo de precisamente / exatamente. Do ponto de vista da análise sintática, este fenómeno justifica a hipótese de que $\mathrm{CP}$ ou ForceP pode marginalmente admitir FocP nas relativas livres.

${ }^{11}$ Para uma apresentação e discussão de propostas sobre a sintaxe das relativas livres, ver, entre outros, Riemsdijk, H. (2007).
} 

com constituintes-wh com núcleo nominal realizado, i.e. discursivamente conectadas (D-Linked), e entram, por isso, com facilidade em alternância com relativas com antecedente, como em(22b): ${ }^{12}$

(22) a. Descobrimos que dificuldades temos de enfrentar.

b. Descobrimos as dificuldades que temos de enfrentar.

Vemos assim que as interrogativas impróprias se caracterizam por várias propriedades (cf. Matos \& Brito 2013):

a. Os predicados da oração subordinante que as selecionam poderem selecionar também frases declarativas ou constituintes nominais como argumento (veja-se descobrimos que há dificuldades / descobrimos algumas dificuldades). Por essa razão, a alternância com um DP seguido de relativa restritiva mostra-se como uma possibilidade, como em (22b).

b. Serem selecionadas por predicados que pressupõem, por parte sujeito da subordinante (ou do locutor), o conhecimento do valor de verdade da proposição subordinada, a qual é, portanto, interpretada como declarativa e não como interrogativa. Como consequência, o seu valor de verdade não pode ser posto em dúvida (veja-se a má formação semântica de (23), diferentemente do que acontece nas interrogativas propriamente ditas, como em $(24)^{13}$ :

(23) \#Descobrimos que dificuldades temos de enfrentar, mas não é verdade que tenhamos de enfrentar qualquer dificuldade.

\footnotetext{
${ }^{12} \mathrm{Um}$ avaliador considerou que casos como o de (22b), quer dizer, um exemplo de relativa com antecedente, deveriam ser considerados como interrogativas reduzidas ou elíticas, pela capacidade de paráfrase com a construção quais $+\mathrm{V}$ ser, paráfrase essa que é geralmente considerada uma das propriedades das interrogativas subordinadas parciais:

(i) Descobrimos quais eram as dificuldade que temos de enfrentar.

Como evidenciado em Matos \& Brito (2013), várias propriedades nos fazem rejeitar esta proposta. Do ponto de vista semântico, se caracterizarmos exemplos como (22a) como interrogativos, teremos de prescindir da ideia de que as interrogativas-wh visam obter informação sobre uma entidade, propriedade ou quantidade de um objeto. De facto, em (22a), o predicado descobrir, na oração declarativa afirmativa subordinante, pressupõe que o sujeito omitido (nós) conhece as dificuldades em causa; o mesmo predicado determina que o seu complemento oracional seja uma asserção verdadeira, como mostra a marginalidade de (23). Ainda do ponto de vista do sentido, apesar de em todos estes exemplos haver possibilidade de alternância com relativas restritivas com antecedente, é entre (22a), Descobrimos que dificuldades temos de enfrentar, e o exemplo (i), Descobrimos quais eram as dificuldade que temos de enfrentar, que se pode falar de sinonímia. Entre (22b), Descobrimos as dificuldades que temos de enfrentar, e (i) não há verdadeiramente sinonímia, como mostrado em Matos e Brito (2013: 113): nas interrogativas impróprias a identificação completa da entidade envolvida é do conhecimento do sujeito matriz, mas não é revelada; pelo contrário, na relativa essa entidade é explicitamente identificada pelo antecedente da relativa. Do ponto de vista lexical, a alternância exibida em (22) é altamente condicionada: predicados como perguntar, inquirir não a admitem, e apenas verbos como descobrir, revelar, ver a aceitam facilmente (para um desenvolvimento desta questão vejase Matos \& Brito 2013).

Quanto à identificação das interrogativas impróprias com as concealed questions/interrogativa reduzidas, como já referido na nota 6, essa identificação é problemática do ponto de vista sintático. Adicionalmente, no que diz respeito aos predicados envolvidos, não existe uma coincidência plena entre os predicados que legitimam as concealed questions e os que sancionam interrogativas impróprias ou relativas restritivas com antecedente: verbos como perguntar ou inquirir podem selecionar DPs numa concealed question (ii), mas não podem selecionar facilmente DPs seguidos de relativa restritiva. Por outro lado, um predicado como descobrir, que legitima interrogativas impróprias, não aceita uma concealed question:

(ii) Perguntei as horas.

(iii) *Perguntei as horas que são.

(iv) Ele descobriu que jogador marcara o golo.

(v) \#Ele descobriu o jogador

Pode então concluir-se que a alternância aqui exibida é uma das propriedades das interrogativas subordinadas parciais impróprias e não pode identificar-se com o fenómeno de interrogativas reduzidas.

${ }^{13}$ Para uma caracterização em termos de significado dos predicados que as legitimam veja-se a proposta de Matos \& Brito (2013). As autoras consideram que os predicados legitimadores das interrogativas impróprias ou falsas interrogativas compreendem os chamados predicados semi-factivos e os predicados fracamente assertivos com conteúdo cognitivo, como descobrir, revelar.
} 

(24) VEles perguntaram que dificuldades temos de enfrentar, mas não é verdade que tenhamos de enfrentar qualquer dificuldade.

(25) a. Descobrimos o que temos de enfrentar.

b. «Durante a última aparição, a 13 de Outubro de 1917, a linda Senhora revelou quem era: a Senhora do Rosário (CETEMPúblico 1.7 v. 7.7, par=ext291250-nd-95b-1)

c. Já se adivinha o que sucedeu (CETEMPúblico 1.7 v. 7.7, par=ext1512885-soc-96a-2)

Estes casos são particularmente interessantes porque apresentam ambiguidade entre a interpretação de interrogativa imprópria ou de relativa livre, como ilustrado para (25a), em (26). Com efeito, como nas interrogativas, o constituinte- $w h$ pode ser focalizado, como em (26a), e pode mesmo ocorrer mais do que um constituinte- $w h$, como em (26b):

(26) a. Descobrimos o que é que temos de enfrentar.

b. Descobrimos quem tem de enfrentar o quê.

Como nas relativas livres, as interrogativas impróprias podem ser aproximadas de relativas com antecedente, como em(27a), e não têm correspondência com estruturas de se interrogativo mais oração: ${ }^{14}$

a. Descobrimos aquilo que temos de enfrentar.

b. ??/*Descobrimos se temos de enfrentar aquilo/alguma coisa.

Em suma, as construções-wh subordinadas presentes nas relativas livres, nas interrogativas parciais subordinadas e nas interrogativas impróprias apresentam semelhanças e podem mesmo representar casos de ambiguidade estrutural. Porém, há diferenças de comportamento destas subordinadas que atestam que se integram em estruturas sintáticas diversas.

\section{As análises clássicas das relativas livres e das interrogativas subordinadas}

Para captar as diferenças de comportamento entre relativas livres e interrogativas parciais subordinadas, na Gramática Generativa pré-minimalista vários autores assumiram que as primeiras apresentam um CP argumento do predicado superior, enquanto as relativas livres exibem um CP integrado num DP.

Assim, para (28a) e (29a) teríamos as representações derivadas esquemáticas(28b) e (29b) (cf. Ambar, 1992; Brito,1991; Móia,1996):

\footnotetext{
${ }^{14}$ Como já referido 2.2. aquando da apresentação da propriedade (iv) (alíneas a, b e c), há predicados que passam a selecionar interrogativas subordinadas em frases negativas, em certos contextos modais e sob o escopo da interrogação da oração matriz. Nessas circunstâncias podemos mesmo encontrar predicados como descobrir seguido de se+oração: (i) Não descobrimos (ainda) se temos de enfrentar aquilo/alguma coisa; (ii) Espero que possamos descobrir um dia se temos (mesmo) de enfrentar aquilo/alguma coisa. Como indicado em Matos \& Brito (2013), mesmo um verbo como dizer, sob o escopo da interrogação da frase matriz (ii) ou do predicado negado da subordinante (iii) pode ser seguido de se+oração:

(ii) Dizes-me, por favor, se vens jantar? (cf. Ele disse-me se vem jantar ou não.)

(iii) Não me conseguiram dizer se vêm jantar. (Cf. \# Conseguiram dizer-me se vêm jantar ou não)
} 

(28) a. Pergunto o que (é que) tu fizeste.

b. [pergunto .... CP ]

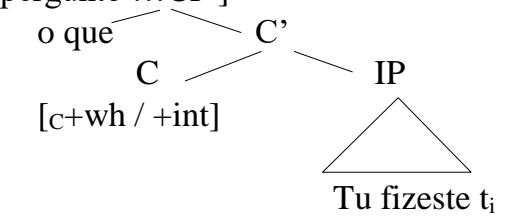

(29) a. Admiro o que fizeste.

b. [admiro ...DP ]

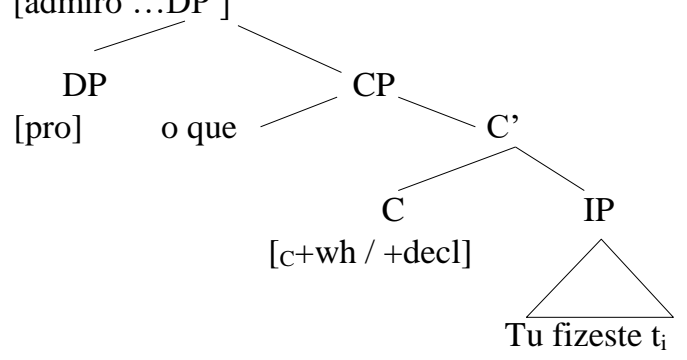

Neste quadro teórico, a ambiguidade entre relativas livres e interrogativas indiretas, bem como entre estas e as interrogativas impróprias, é captada, em particular, pelas propriedades do predicado que seleciona a subordinada e a natureza declarativa ou interrogativa de C. Assim, em (28), o predicado superior é perguntar e temos uma interrogativa indireta; por outro lado, em (29) há um predicado não interrogativo como admirar e temos uma relativa livre; por fim, em (30) há um predicado fracamente assertivo com conteúdo cognitivo como descobrir, pelo que temos uma interrogativa imprópria ou uma falsa interrogativa, como proposto e justificado detalhadamente em Matos \& Brito (2013):

(30)

a. Descobri o que (é que) tu fizeste.

b. [descobri ....CP ]

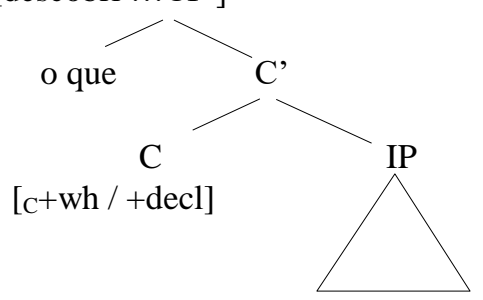

tu fizeste $t_{\mathrm{i}}$

\section{As propostas do Programa Minimalista: Compor, Estrutura Sintagmática Nua e Etiquetagem}

No Programa Minimalista a análise clássica apresentada tem de ser repensada e tem de ser avaliada a capacidade de este novo quadro teórico dar conta destas construções.

No Programa Minimalista atual (em particular, em Chomsky, 1995: cap. 4, 2008, 2013, 2015) as operações, os princípios e as representações sintáticas são reduzidas aos elementos que desempenham um papel na interpretação das expressões linguísticas ao nível das interfaces Fonológica e Semântica. Como consequência: 

A Teoria X-barra é abandonada, uma vez que os seus níveis de representação, nomeadamente os níveisbarra não são interpretáveis nas interfaces. Em alternativa, o esqueleto estrutural das frases é construído pela operação de Compor, associada à Estrutura Sintagmática Nua e ao mecanismo de Etiquetagem.

(i.a) Compor (Merge):

Compor é uma operação binária que associa dois objetos sintáticos, $\mathrm{X}$ e $\mathrm{Y}$, para formar um novo objeto sintático [X,Y], tal como descrito em (31):

(31) a. Objetos: $[\mathrm{X}],[\mathrm{Y}]$

b. Compor:

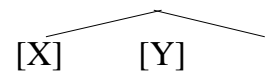

Compor aplica-se recursivamente, construindo debaixo para cima (bottom-up) para gerar a estrutura frásica.

(i.b) Estrutura Sintagmática Nua (Bare Phrase Structure):

A Estrutura Sintagmática Nua exclui a existência de notação categorial nas representações sintáticas diversas da das categorias lexicais, as únicas com conteúdo interpretável na componente Semântica.

Assim, em (31b), o objeto sintático composto será categorialmente idêntico a um dos objetos (X ou Y) que o compõem.

(i.c) Mecanismo de Etiquetagem (Labelling):

Segundo o mecanismo de Etiquetagem, uma projeção herda os traços categoriais do seu núcleo.

(32)

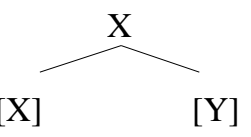

Consequentemente, a distinção entre núcleo e sintagma não é inerente aos objetos sintáticos e é inferida pela posição que ocupam relativamente ao núcleo. Em (32), Y pode ser interpretado como um sintagma, uma vez que não é núcleo da projeção de $X$.

A etiquetagem obedece a um requisito de localidade; o algoritmo de etiquetagem (labelling algorithm), formulado por Chomsky $(2013,2015)$ requer que o núcleo sintático que atribui a etiqueta seja o mais local em termos de estrutura hierárquica. Assim, embora os objetos $\mathrm{X}$ e Y sejam núcleos, é $\mathrm{X}$, e não $\mathrm{Y}$, que atribui a etiqueta à estrutura em (33):

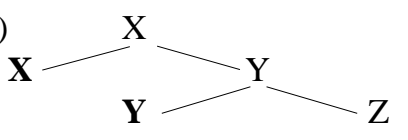

A operação de movimento de constituintes é designada como Compor Interno (InternalMerge) no Programa Minimalista atual, e é desmembrada nas operações de Compor (Merge) e Concordar (Agree).Esta operação retoma um elemento já presente numa estrutura formada e insere-o numa posição estrutural mais elevada (cf. Chomsky, 2008, 2013), deixando uma cópia, que será apagada na interface fonológica. 



\section{Derivação de relativas livres e interrogativas subordinadas}

Vemos assim que, adotando o Programa Minimalista, que constrói a estrutura das frases de baixo para cima, a ambiguidade estrutural de relativas livres e de interrogativas subordinadas, bem como as suas diferenças, tem de ser captada de modo diverso do da análise clássica que constrói a estrutura de cima para baixo. Nessa medida, têm sido propostas análises alternativas às apresentadas no ponto 3. Destacaremos a análise de Donati \& Cecchetto.

\subsection{A proposta de Donati \& Cecchetto}

Cecchetto \& Donati (2010) e Donati \& Cecchetto (2011) atribuem a ambiguidade das estruturas encaixadas presentes em interrogativas parciais subordinadas e relativas livres ao estatuto de núcleo do constituinte-wh envolvido. Como os autores fazem notar, uma frase subordinada como what you read, (34), em si mesma, é ambígua, podendo ser interpretada como relativa livre, como no caso de (35),ou como interrogativa subordinada, como no caso de(36); pelo contrário, what book you read, em (37), com um sintagma-wh e não um núcleo-wh, só pode ser uma interrogativa subordinada:

(34) [ V ... [what you read] ]

(35) I read what you read.

(36) I wonder what you read.

(37) I wonder what book you read.

Concluem, então, que o movimento de núcleo dá sempre lugar a ambiguidade estrutural, pois um tal constituinte pode ser interpretado como núcleo ou como sintagma. Assim, as estruturas resultantes do movimento- $w h$ podem ser etiquetadas de duas formas distintas:

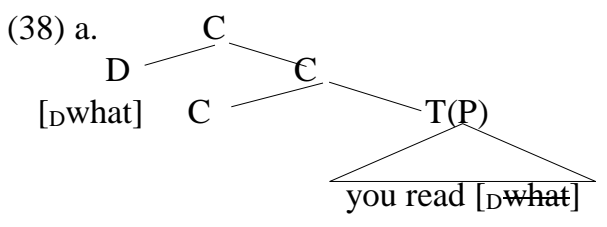

b.

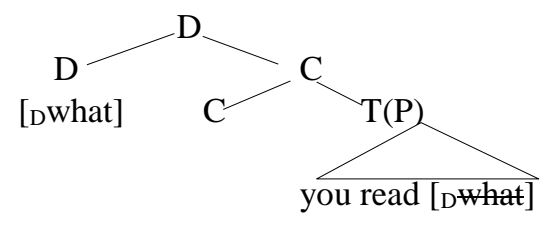

Em (38a), teremos uma interrogativa subordinada porque a etiqueta resultante é $\mathrm{CP}$ decorrente do núcleo C; em (38b) teremos uma relativa livre porque a etiqueta resultante do movimento do núcleo $\mathrm{D}_{\mathrm{wh}}$ DP.

Pelo contrário, o movimento de um sintagma não cria estruturas ambíguas, pois a estrutura resultante herda unicamente a categoria (etiqueta) do núcleo da estrutura, sendo, por isso, interpretada como CP e por isso como uma interrogativa:

(39)

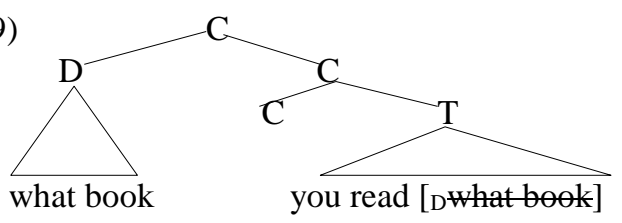





\subsection{Derivação de relativas livres e interrogativas subordinadas no $P E$}

A aplicação da proposta de Donati \& Cecchetto parece captar adequadamente os casos em que temos apenas como constituinte- $w h$ um núcleo, como é o caso de quem. Porém, a proposta também suscita alguns problemas:

1. Poderá o que, que introduz subordinadas que, à partida, são estruturalmente ambíguas, ser analisado como um núcleo?

2. Para dar conta da ambiguidade da subordinada nas relativas livres e nas interrogativas próprias e impróprias bastará a distinção entre núcleo e projeção máxima?

Estes dois problemas serão seguidamente discutidos.

\subsection{1. "O que” é um núcleo lexical?}

Como é sabido, os constituintes interrogativos são considerados tradicionalmente pronomes ou advérbios interrogativos e por isso tidos como palavras, como núcleos. Num quadro pré-minimalista, Ambar (1992), embora referindo que formas como o que, quem, quando, onde, como são expressões-wh simples, assume que são sintagmas. Por sua vez, esses sintagmas-wh são analisados como incluindo um núcleo vazio, com os traços [ \pm humano, + tempo, + lugar, + maneira, etc....].

$$
\text { o que: [whP o que [ [-hum - ] ] }
$$

Segundo Ambar, esse núcleo vazio teria de ser adequadamente regido na posição inicial da frase (especificador de CP), o que motivaria o movimento do verbo para $\mathrm{C}$, como ilustrado em (41). Como se sabe, (41a) é agramatical e só (41b) é gramatical em PE. Porém, o movimento do V não é necessário se tivermos sintagmas-wh com um núcleo realizado, designados na literatura como sintagmas discursivamente conectados (D-linked), como, por exemplo, que disparates em (42):

(41) a. [cp O que [c fez] a criança ]?

b. *O que a criança fez?

(42) [ср Que disparates [тр a criança fez] ]?

Ora, no Programa Minimalista não subsiste o conceito de regência e, por essa razão, a explicação de Ambar para a obrigatoriedade do movimento do $\mathrm{V}$ em interrogativas $w h$ tem de ter uma alternativa.

Admitamos, em primeiro lugar, que $o$ que interrogativo pode ser analisado como um núcleo lexical (composto). ${ }^{15}$ Procurando compatibilizar a análise de Ambar com a proposta de Cecchetto \& Donat, propomos

${ }^{15}$ Para o português, a análise de $o$ que interrogativo como núcleo tem sido proposta por diversos autores, tanto em interrogativas independentes como em subordinadas (ver, entre outros Brito 1991, Móia 1996, Alexandre 2000, Brito e Duarte 2003: 682) pelo facto de comutar com que:

(i) O que fizeste? / Que fizeste?

(ii) Perguntei o que fizeste / Perguntei que fizeste.

Nas relativas livres, porém, tal comutação é impossível (iii). Por outro lado, os seus elementos podem ser separados por preposição em certas circunstâncias (iv); contudo, noutros contextos, como notado por um avaliador, esta separação por preposição é impossível, (v), o que indica que, nestes casos, formam uma unidade:

(iii) *Aprecio que fizeste / Aprecio o que fizeste.

(iv) Já tenho o de que me falaste (como alternativa a Já tenho aquilo de que me falaste, uma relativa com antecedente).

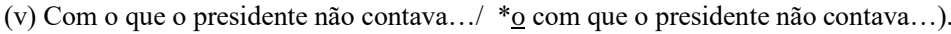

Há ainda diferenças, quer diacrónicas, quer entre variantes do português (PE vs PB), que exigiriam um estudo mais detalhado sobre a natureza categorial de $o$ que.

No entanto, como notado por um avaliador, uma questão deve ser clarificada: se que é um núcleo, então deveria poder ocorrer em relativas livres, o que não acontece, como mostrado em (iii). Adotamos a proposta de Brito (1991): dada a existência de que complementador, parece operar sobre que um requisito de identificação de conteúdo. 
que $o$ que é um núcleo nominal, mais propriamente um $\mathrm{D}_{\mathrm{wh}}$ que resulta da incorporação (merge) de um núcleo nominal com o traço [N -hum], como descrito em (43):

\section{(43) [Dwh [-hum [Dwho_que]] [-hum]]}

Assim, vamos admitir que o que é um núcleo. ${ }^{16}$ Sendo um núcleo, tanto pode ser interpretado como sintagma e ser integrado numa estrutura que recebe a etiqueta $\mathrm{C}$, dando origem a uma interrogativa subordinada, como pode atribuir a sua etiqueta $\mathrm{D}$ à estrutura derivada, dando origem a uma relativa livre. É o que descrevemos em (44) e (45).

(44) a. Pergunto o que fizeste. (interrogativa subordinada)

b. Admiro o que fizeste. (relativa livre)

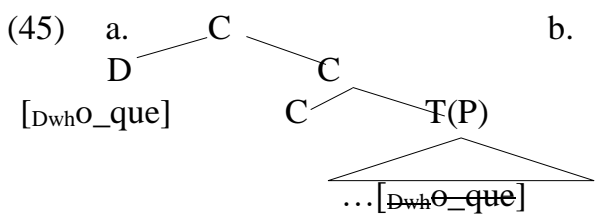

b.

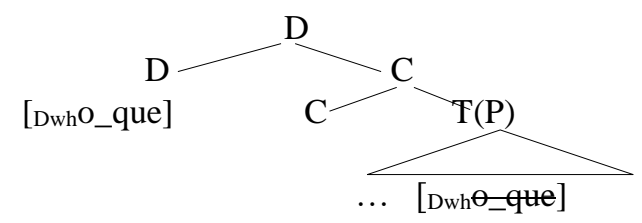

Em segundo lugar, importa revisitar o movimento do $\mathrm{V}$ para C. Admitimos que o movimento do verbo para $\mathrm{C}$ em frases raiz pode ter a ver com etiquetagem.

Consideremos primeiramente frases como (41b). Neste caso, estamos perante configurações como (46), em que tanto D como C são núcleos igualmente locais do nó cimeiro “?”, criando um conflito de etiquetagem deste nó como $\mathrm{D}(\mathrm{P})$ ou $\mathrm{C}(\mathrm{P})$ :

(46) a. *O que a criança fez?

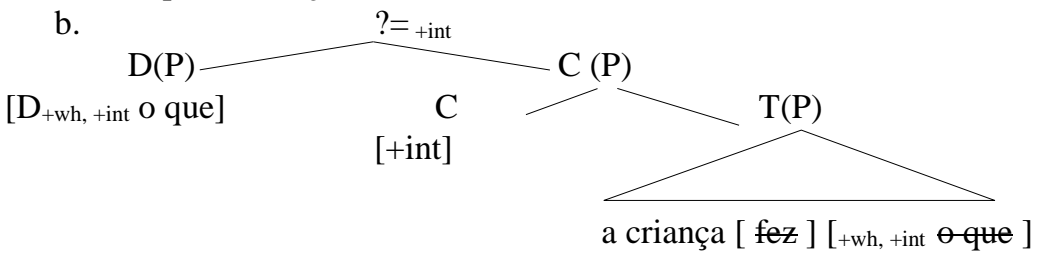

Rizzi (2016) considera que o traço [+int] caracteriza o D(P) interrogado (cf. (46b)). Ao mover-se para o domínio $C$, os núcleos $D_{\text {wh }}$ e $C$ são ambos locais relativamente a "?" e partilham o traço [+int]. Esta etiqueta partilhada deve ser herdada pelo núcleo (Chomsky, 2013, 2015; Rizzi, 2016b) cimeiro da estrutura (46), i.e.

Este mesmo requisito de identificação ocorre com que interrogativo, inclusive em frases subordinadas. Dada a sua falta de especificação lexical só é possível em PE quando o sujeito é explícito, com movimento do V para C (Ambar 1992):

(v) Pergunto que fez a Maria

(vi) *Pergunto que a Maria fez.

Esta possibilidade / impossibilidade corrobora a nossa proposta de que o movimento do verbo para C em frases raiz pode ter a ver com etiquetagem.

${ }^{16}$ Em PB os dados não são idênticos e (41b) é bem formado. Ver nota seguinte. 
“?”adquire a natureza [+interrogativa]. Porém, este mecanismo de partilha de traços por si só não chega para que (46a) corresponda a uma frase bem formada no PE.

Note-se, contudo, que $\mathrm{C}$ é intrinsecamente marcado com traços de força ilocutória da frase, no caso [+int]. Admitimos, assim, que o movimento do verbo para C em (41a), representado em (47), é uma das estratégias do PE para marcar abertamente o estatuto de núcleo de C, obrigando a que "?" seja identificado como $\mathrm{C}_{\text {+int }}(\mathrm{P})$ :

(47) a. O que fez a criança?

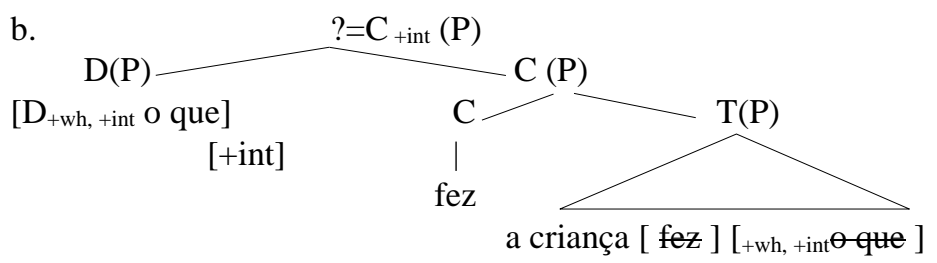

Assim, colocamos como hipótese que o contraste de gramaticalidade entre $(41 \mathrm{a})=(46 \mathrm{a})$, sem movimento do V-I para C, e $(41 b)=(47 b)$, com movimento de V-I para C, pode decorrer do mecanismo de etiquetagem (Chomsky, 2013, 2015, Rizzi 2016a,b, no prelo). ${ }^{17}$

Note-se, no entanto, que nas frases interrogativas subordinadas é possível a ausência de subida do verbo para C. Debruçar-nos-emos sobre estas construções na próxima subsecção.

\subsubsection{As relativas livres, as interrogativas subordinadas e seleção do predicado superior}

Nos parágrafos anteriores, procurámos derivar a natureza de interrogativa parcial subordinada e de relativa livre a partir de condições formais de etiquetagem, quer ligadas à natureza de núcleo ou projeção máxima do constituinte-wh movido, quer ligadas ao movimento do $\mathrm{V}$ para $\mathrm{C}$, explorando hipóteses recentes de Cecchetto \& Donati.

Contudo, vimos que a distinção entre núcleo e projeção máxima do constituinte-wh não basta para distinguir relativas livres de interrogativas parciais subordinadas. Além disso, recorde-se, há uma distinção entre interrogativas parciais subordinadas verdadeiras ou próprias e as interrogativas parciais subordinadas impróprias ou falsas interrogativas parciais. Parece, então, que a natureza $\mathrm{D}(\mathrm{P})$ ou $\mathrm{C}(\mathrm{P})$ do constituinte da subordinada e a sua natureza interrogativa [+int] ou declarativa [+decl] tem de ser sancionada pela seleção do predicado superior. Recordem-se os exemplos relevantes:

(48) a. Perguntei o que fizeste.

b. Descobri o que fizeste.

c. Admirei o que fizeste.

A ambiguidade estrutural e semântica dos exemplos (48) não decorre apenas da natureza de núcleo ou de sintagma do constituinte-wh, aliás sempre o mesmo o que (que analisámos como um núcleo lexical composto), mas dos traços de seleção dos predicados que são com eles combinados (merged). Ou seja, é

\footnotetext{
${ }^{17}$ Esta explicação enfrenta o problema de no PB o movimento do V para C não ser obrigatório nas interrogativas-wh. Ambar, Negrão, Veloso e Graça (2009) desenvolvem um tratamento alternativo, defendendo que o PB não tem movimento do $\mathrm{V}$ para $\mathrm{C}$ porque o $\mathrm{V}$ não se move para fora de $\mathrm{vP}$, enquanto o $\mathrm{PE}$ tem movimento de $\mathrm{V}$ para $\mathrm{C}$ porque o $\mathrm{V}$ pode mover-se para fora de $\mathrm{vP}$. Não desenvolveremos aqui com profundidade esta questão.
} 

crucial a compatibilidade/incompatibilidade destes predicados com $\mathrm{C}(\mathrm{P})$ ou $\mathrm{D}(\mathrm{P})$, e, no caso de poderem selecionar $\mathrm{C}$, da sua compatibilidade com a força ilocutória de $\mathrm{C}$, interrogativa ou declarativa. ${ }^{18}$

Uma vez que esta combinação com um predicado relevante sanciona a natureza categorial do constituinte sintático, admitimos que, no caso das interrogativas-wh encaixadas, como (9), a opcionalidade do movimento do verbo se deve ao facto de esse movimento não ser necessário como forma de etiquetar a estrutura formada como $\mathrm{CP}^{19}$ :

(49) a. Pergunto o que a Maria fez.

b. Pergunto o que fez a Maria.

\section{Conclusões}

Neste artigo analisámos semelhanças e diferenças sintáticas entre relativas livres, interrogativas parciais subordinadas verdadeiras ou próprias, assim como interrogativas parciais subordinadas impróprias ou falsas interrogativas parciais. Essas diferenças corroboram as análises clássicas, segundo as quais as relativas livres são DPs que contêm uma oração (CP), enquanto as interrogativas parciais subordinadas próprias e impróprias são CPs. De forma a enquadrar esta análise no quadro do Programa Minimalista, discutimos as propostas de Cecchetto \& Donati (2010) e Donati \& Cecchetto (2011), que propõem que a natureza DP ou CP de uma dada construção pode ser deduzida de condições formais de etiquetagem, sobretudo ligadas à natureza de núcleo ou projeção máxima do constituinte-wh movido. No artigo, procurámos mostrar que esta distinção é importante e relacionámo-la com o movimento do V em interrogativas, desenvolvendo Ambar (1992) em termos do quadro Minimalista atual. No entanto, embora aceitando a importância da distinção entre núcleo e projeção máxima do constituinte-wh para a etiquetagem das estruturas obtidas, mostrámos que a natureza DP ou CP da subordinada e a sua natureza interrogativa [+int] ou declarativa [+decl] não prescinde da análise clássica de compatibilidade com os traços de seleção do predicador superior.

\section{Referências}

Alexandre, Nélia (2000) A estratégia resumptiva em relativas restritivas do Português Europeu. Tese de mestrado, Faculdade de Letras da Universidade do Porto.

Ambar, Manuela (1992) Para uma Sintaxe da Inversão Sujeito Verbo em Português. Lisboa: Edições Colibri.

\footnotetext{
${ }^{18}$ Um avaliador assume que a distinção entre interrogativas subordinadas próprias e impróprias e relativas livres baseada na natureza do predicado superior não é compatível com o mecanismo de derivação por fases do Programa Minimalista, que procede de baixo para cima. Consideramos que a questão levantada não coloca um problema à análise esboçada. Embora o CP subordinado seja uma fase, a derivação da frase em que está encaixado não terminou. Esse CP está integrado como um argumento do predicado superior (no caso das interrogativas próprias e impróprias) ou como um modificador restritivo (não parentético) do DP omitido selecionado pelo CP da frase subordinante. Ou seja, para que a derivação da fase superior não aborte é necessário que Merge associe o CP da fase subordinada a um núcleo que com ele tenha traços compatíveis. Assim sendo, a derivação continua fase a fase debaixo para cima, até ao CP da frase subordinante.

19 Porém, como notado em Brito 1991, Ambar 1992, quando o constituinte-wh é que, o movimento do verbo é requerido nas interrogativas subordinadas:

(i) *Pergunto que a Maria fez;

(ii) Pergunto que fez a Maria.

Para explicar este contraste, podemos possivelmente alegar que que corresponde tanto à forma do complementador que introduz as frase finitas, como a um morfema $w h$. Para ser interpretado como morfema-wh, o movimento do $\mathrm{V}$ é necessário para que a categoria formada seja de facto etiquetada como $\mathrm{C}_{+ \text {int }}(\mathrm{P})$.
} 

Ambar, Manuela, Negrão, E., Veloso, R., Graça, L. (2009) Tense domains in BP and EP - vP, CP and phases. In Enoch O, E. Linden, J. Quer \& P. Sleeman (eds.) Romance Languages and Linguistic Theory: Selected papers from 'Going Romance' Amsterdam 2007, pp. 1-24, https://doi.org/10.1075/rllt.1.01amb

Brito, Ana Maria (1991) A sintaxe das orações relativas em Português. Estrutura, mecanismos interpretativos e condições sobre a distribuição dos morfemas relativos. Porto: Instituto Nacional de Investigação Científica.

Brito, Ana Maria \& Inês Duarte (2003) Orações relativas e construções aparentadas. In Maria Helena Mateus, Ana Maria Brito, Inês Duarte, Isabel Hub Faria, Sónia Frota, Gabriela Matos, Fátima Oliveira, Marina Vigário \& Alina Villalva (2003) Gramática da Língua Portuguesa, 6a ed., Lisboa: Caminho, pp. 675 684.

Cardoso, Adriana \& Nélia Alexandre (2013) Relativas clivadas em variedades não standard do português europeu. In Fátima Silva; Isabel Falé \& Isabel Pereira (orgs.) Textos Selecionados do XVIII ENAPL, 2012, Porto: APL, pp. 205-227.

Cecchetto, Carlo \& Caterina Donati (2010) On labeling: Principle C and head movement, Syntax, 2010, DOI: 10.1111/j.1467-9612.2010.00140.x

Cecchetto, Carlo \& Caterina Donatti (2015) (Re)labeling,Linguistic Inquiry Monographs, MIT Press.

Chomsky, Noam (2008) On phases. In Freidin, Robert, Otero, Carlos \& Maria-Luisa Zubizaretta, M. L. (eds.) Foundational Issues in Linguistic Theory, Cambridge, MA: MIT Press.

Chomsky, Noam (2013) Problems of Projection. Lingua, 130, pp. 33-49.

Chomsky, Noam (2015) Problems of Projection: Extensions. In Elisa Di Domenico, Cornelia Hamann, Simona Matteini (eds.) Structures, Strategies and Beyond - Studies in Honour of Adriana Belletti. Amsterdam/Philadelphia: John Benjamins, pp. 3-16.

Donati, Caterina \& Carlo Checcetto (2011) Relabeling heads. A unified account for relativization structures. Linguistic Inquiry, 42:4, pp. 519-560.

Matos, Gabriela \& Ana Maria Brito (2013) The alternation between improper indirect questions and DPs containing a restrictive relative. In Camacho-Aboada, Victoria, Angel Jimenéz-Fernández, Javier MartínGonzáles \& Mariano Reyes-Tejedor (eds.) Information Structure and Agreement, Amsterdam: John Benjamins, pp. 83-116.

Mioto, Carlos \& Maria Lobo (2016) Wh movement: interrogatives, relatives and clefts. In W. Leo Wetzels, Sergio Menuzzi \& João Costa (eds.) The Handbook of Portuguese Linguistics. Wiley-Blackwell, pp. 275293.

Móia, Telmo (1996) A sintaxe das orações relativas sem antecedente expresso do Português. In Anabela Gonçalves, Madalena Colaço, Matilde Miguel \& Telmo Móia, Quatro estudos em sintaxe do Português. Uma abordagem segundo a teoria dos princípios e parâmetros. Lisboa: Edições Colibri, pp. 149-188.

Peres, J. \& Móia, T. (1995) Áreas Críticas da Língua Portuguesa, Lisboa: Editorial Caminho.

Riemsdijk, H. (2007) Free Relatives. In Everaert, M. \& van Riemsdijk, H. (eds.) The Blackwell Companion to Syntax, Blackwell, pp. 338-382.

Rizzi, Luigi (1997) The Fine Structure of the Left Periphery. In Liliane Haegeman (ed.) Elements of Grammar: A Handbook of Generative Syntax. Dordrecht: Kluwer, pp. 281-337.

Rizzi, Luigi (2016a) Labeling, maximality and head - phase distinction. Linguistics Review 33(1), pp. 103127.

Rizzi, Luigi (2016b) EPP and ECP revisited: The role of labeling. In Ernestina Carrilho, Alexandra Fiéis, Maria Lobo \& Sandra Pereira (eds.) Romance Languages and Linguistic Theory 10. Selected papers from 'Going Romance' 28, Lisbon, by [RLLT 10], pp. 211-231.

Rizzi, Luigi (no prelo) The left periphery: Cartography, Freezing, Labeling. In Proceedings of the International Workshop on Syntactic Cartography. Beijing: Beijing Language and Culture University. 

Suñer, Margarita (1991) Indirect Questions and the structure of CP: Some consequences. In Héctor Campus \& Fernando Martínez-Gil (eds.) Studies in Romance Linguistics. Dordrecht, Foris Publications, pp. 183-203.

Suñer, Margarita (1993) About indirect questions and semi-questions. Linguistics and Philosophy, 16, pp. 4577.

Suñer, Margarita (1999) La subordinación sustantiva: la interrogación indirecta. In Ignacio Bosque \& Violeta Demonte (eds.) Gramática Descritiva de la Lengua Española. Madrid:Espasa, pp. 2147-2195.

Veloso, R. (2013) Subordinação relativa. In Raposo, E.P. et al., Gramática do Português. Lisboa: Fundação Calouste Gulbenkian, Vol. II, pp. 2061-2134. 